\title{
Economic analysis of drought risk: An application for irrigated agriculture in Spain
}

\author{
Marina Gila ${ }^{a}$ Alberto Garrido ${ }^{a, *}$, Almudena Gómez-Ramos ${ }^{\mathrm{b}}$ \\ ${ }^{a}$ Research Centre for the Managament of Agricultural and Environmental Risks (CEIGRAM), Technical University of Madrid, Spain \\ ${ }^{\mathrm{b}}$ University of Valladolid, Spain
}

\begin{abstract}
A B S T R A C T
This paper describes a two-part methodology for managing the risk posed by water supply variability to irrigated agriculture. First, an econometric model is used to explain the variation in the production value of irrigated agriculture. The explanatory variables include an index of irrigation water availability (surface storage levels), a price index representative of the crops grown in each geographical unit, and a time variable. The model corrects for autocorrelation and it is applied to 16 representative Spanish provinces in terms of irrigated agriculture. In the second part, the fitted models are used for the economic evaluation of drought risk. Inflow variability in the hydrological system servicing each province is used to perform ex-ante evaluations of economic output for the upcoming irrigation season. The model's error and the probability distribution functions (PDFs) of the reservoirs' storage variations are used to generate Monte Carlo (Latin Hypercube) simulations of agricultural output 7 and 3 months prior to the irrigation season. The results of these simulations illustrate the different risk profiles of each management unit, which depend on farm productivity and on the probability distribution function of water inflow to reservoirs. The potential for ex-ante drought impact assessments is demonstrated. By complementing hydrological models, this method can assist water managers and decision makers in managing reservoirs.
\end{abstract}

\section{Introduction}

Droughts create periods of water scarcity that affect all urban, industrial, and agricultural water supply systems, and they disturb the flow of environmental services. Water infrastructures alleviate the effects of meteorological droughts, but it requires efficient management of reservoirs and aquifers and demand management (Iglesias et al., 2007, 2009). Any model or protocol designed to mitigate the effects of water scarcity requires accurate information about the social and economic consequences of droughts. The incorporation of risk analyses into resource management thus requires precise knowledge of the economic impact of droughts at the basin level and on a smaller scale (Iglesias et al., 2009).

Garrido and Gómez-Ramos (2009) reviewed economic instruments that can be applied to drought risk management. Among them, Gómez-Ramos and Garrido (2004) proposed an option contract to distribute supply risk between users with different levels of flexibility, thus accommodating lower application rates by irrigators while ensuring urban supply. Drought risk can be analyzed by linking scarcity risk with the economic productivity of water, which is expressed in terms of social, environmental and/or economic services (Iglesias et al., 2003). Uncertainty about future water availability is transferred to the value and commercial uses of the eco-system.

A number of studies analyzing the economic impact of droughts use mathematical programming models to simulate economic impact (Iglesias et al., 2003; Calatrava and Garrido, 2005; Salami et al., 2009; Peck and Adams, 2010). Others use econometric models fitted at the macroeconomic level (Alcalá Agulló and Sancho Portero, 2002; Martínez-Cachá, 2004) or at the level of the irrigation district (Lorite et al., 2007), the irrigated farm (Rubio Calvo et al., 2006) or single crops (Quiroga and Iglesias, 2009). Input-output models have also been used to study the regional effects of water scarcity (Pérez y Pérez, 2007). Finally, other authors have used computable general equilibrium models (Berrittella et al., 2007; Gómez et al., 2004; Goodman, 2000). With the exception of Iglesias et al. (2003), none of these authors has used a model to predict the impact of future droughts.

The use of mathematical programming models must overcome the calibration problem, which, in most cases is performed with reference to a number of representative units (typically farms) (Iglesias and Blanco, 2008), one or very few periods (in most cases), or behavioral features such as risk aversion (Mejías et al., 2004). In these models, the simulated economic value results from optimiz- 
ing the allocation of available resources (land, water, and labor) subject to observed constraints. The resource constraint can be assumed to be stochastic (as in Iglesias et al., 2003; Calatrava and Garrido, 2005), which enables dynamic models for optimizing water allocation over a number of seasons (Iglesias et al., 2007).

Computable general equilibrium models (CGE) serve as an analytical tool, but most of the parameters, such as elasticities and the coefficients of production functions, quickly become outdated. Gómez et al. (2004) evaluated the economic impacts of various allocative criteria in the Balearic Islands using the National Agricultural Accounting Network and the input-output tables for 1997, on which future scenarios were evaluated. The simulation results of Berrittella et al. (2007) are based on a version of the Global Trade and Analysis (GTA) using data for 1997. The potential to productively inform actual management criteria for scarce resources diminishes as the lapse between the reference year used for model calibration and the projection period expands.

In this paper, we develop an alternative approach to (1) evaluate the economic impact of droughts and (2) obtain ex-ante economic risk evaluations for commercial users (farmers) relying on uncertain water sources. Our approach complements previous analyses in two ways. The economic impacts are calculated directly from observed cropping patterns, yields, and water consumption and are evaluated with the prevailing prices in each season. They are not estimated and do not result from optimization models. By focusing the analysis on observed economic output at the provincial level, we avoid the need to assume fixed production technologies (as in CGE models) or fixed resource constraints (as in optimization models). Furthermore, our modeling approach isolates the effects of economic production of the passage of time (trend) and crop price variations (farm products) from the effect of actual water availability. This is the only variable that water managers can control.

The second feature that differentiates our approach from previous works is that we analyze the stochastic water sources in detail and link them with the economic drought impact model. As a result, water and irrigation managers not only have easily interpretable ex-ante probability measures of water availability that can be revised periodically, but they also have ex-ante probability measures of the economic output that can be obtained from the available water.

The aim of this paper is twofold. First, we develop a droughtimpact attribution model based on an econometric model to explain the variability of the economic performance of irrigated agriculture. This allows us to determine which percentage of farmers' production variation can be attributed to irrigation water availability. The second objective is to develop a simple methodology to obtain ex-ante probability distribution functions of the economic production value months before the start of the season. With Monte Carlo simulations, in which stochastic inflows into the reference reservoirs provide the main source of economic risk, we develop a method to inform water managers about the expected revenues that can be obtained by irrigators. The method can be used to simulate the economic impacts of alternative water storage management decisions, which is a widely recognized prerequisite to put drought mitigation plans in practice (Iglesias et al., 2009). The methodological approach is applied to the 16 most important Spanish provinces for irrigation, which are representative of all major geographic Iberian basins.

This article consists of four sections. In Section 2, the methods are presented. These include (1) the econometric models, which provide the attribution model of economic drought effects and (2) the risk analysis. Subsequently, we present the economic and hydrological variables and the geographical scope of the paper. The most relevant results are presented in Section 4, while Section 5 summarizes the impact on water management of economic drought risk.

\section{Methods}

To measure the economic effects of drought on irrigated agriculture, we need to identify the main variables that explain the observed variation in irrigation production value. A water variable is needed to identify droughts and scarcity periods. For this purpose, we selected the storage levels of reservoirs for two reasons: on the one hand, this is the main variable used in the Spanish Drought Plans, and on the other it is monitored and updated on a weekly basis. This variable also provides the most objective and transparent indicator of farmers' irrigation water availability.

The methodological approach has two components. First, an econometric model is fitted to explain the variation in the irrigated production value due to water availability. This general model is subsequently applied to each of the 16 provinces studied. The province level is the unit of analysis because specific farm data are recorded at this level and also because provinces and specific storage capacity can be unambiguously linked. As there are no reliable databases for production costs at the level of our analyses, we focus only on farmers' revenue. However, for the purpose of our study (obtaining ex-ante economic projections), the only relevant sources of variation are crop yield, crop price, available water (which informs cropping patterns and acreage decisions) and other non-controllable factors.

The second methodological component takes the econometric model as a basis for a risk model, which introduces the current variability of water inflow to each storage system. The economic risk of drought is simulated based on the stochasticity of the supply source of irrigation water to obtain ex-ante economic projections.

The structure of the model produces a simple but complete tool focused on measuring economic losses due to water scarcity and isolating them from crop prices variability. All of the efforts will be focused on irrigated production value as a general measure of the economic output of the sector.

\subsection{Econometric model}

The econometric model explains the variation in the economic value of harvests from an irrigated area (irrigated production value) as a function of water availability, a time variable (trend) and a price index. This is a general model in which the variable to be explained is $I P V_{i t}$ (irrigated production value) estimated for each year (index $t$ ) and each province (index $i$ ). The statistical model is defined for each province $i$ as follows:

$$
\begin{gathered}
I P V_{i t}=a_{i}+b_{i} T_{i}+c_{i} R_{i t}+d_{i} G_{i t}+e_{i} I p_{i t}+u_{i t} \\
\text { with } u_{i t}+\varepsilon_{i t}+\rho_{i} \varepsilon_{i t-1} ; \quad E\left(\varepsilon_{t}\right)=0 \text { and } \sigma_{\varepsilon i}^{2}=\sigma_{i}^{2}
\end{gathered}
$$

where $T_{t}$ is the time variable expressed in years, $R_{i t}$ is the hydrological variable expressed in \% reservoir capacity, $G_{i t}$ is groundwater levels (only in the provinces where groundwater provides a significant proportion of irrigation water) and $I p_{i t}$ is a price index for each province.

$I P V_{i t}$ is the production value calculated from data on irrigated area and crop yields along with annual crop prices. Therefore, it is expressed in thousands of current euro and is calculated as the sum of the 94 irrigation crops as follows:

$I P V_{i t}=\sum_{j=1}^{94}$ Suf $_{j t} \times$ Yield $_{j t} \times p_{j t}$

where $S u f_{j t}$ is the irrigated surface in province $i$, year $t$, and crop $j$ $(j=1, \ldots, 94)$, Yield $j t$ denotes the yield of each crop in province $i$ and year $t$, and $p_{j t}$ is the price for each crop in year $t$ evaluated at the farm gate. 
The explanatory variable $R_{i t}$ corresponds to the percentage storage level of reservoirs in the basin where each province is located as measured on May 1 every year. $R_{i t}$ is calculated from actual levels measured in cubic hectometers $\left(\mathrm{hm}^{3}\right)$ divided by total capacity in $\mathrm{hm}^{3}$. The data are obtained from the MARM Monthly Hydrological Bulletin between 1994 and 2009. The selected date (May 1) for the econometric model is considered a valid indicator of the total water available before irrigation starts. In the provinces where groundwater is the main irrigation source, $R_{i t}$ corresponds to underground water levels measured on May 1.

A weighted price index for each geographical unit (denoted by $I p_{i t}$ ) has been calculated to capture the variations in product value due to crop price variations. This index takes into account the importance of each group of crops within each unit and is calculated using the following formula:

$I p_{i t}=\frac{\sum_{k=1}^{12} I P V_{-} t c_{i k t} \times I p_{k t}}{I P V_{i t}}$

where IPV $t c_{i k t}$ is the total value of crop group $k(k=1, \ldots, 12)$, which is representative of the crops grown in each province. All 94 crops were included in these 12 groups so that each group has a specific price index, I $p_{k t}$, which is published by the official statistical source (MARM, 1995-2007). An alternative option would be to evaluate the variable $I P V_{i t}$ in real euros (constant euros) by dividing it with a price index such as $I p_{i t}$. However, a nominal evaluation (in current euros) of $I P V_{i t}$ as defined by Eq. (2) has two advantages. First, both farmers and water managers understand economic evaluations better in nominal terms. Second, the effect of price variation is isolated from the effects of time and of water availability.

Estimates of Eq. (1) were performed using the Prais-Winsten method for time series data. The Durbin-Watson statistic was calculated and the effect of serial correlation errors was corrected. Potential multicollinearity between $R, I p$ and $T$ was tested by measuring the Variance Inflation Factor (VIF).

The econometric model has been formulated to measure the relationship between the availability of water and the final economic output independent of farmer decision processes. We assume that farmers optimize the resources they are given to irrigate their crops, and we take past observed productivity as the basis for predicting farm productivity in the short term. However, in the second part of the methodology, the work is focused on risk assessment. For this purpose, we will take into account the conditions prior to the start of each irrigation season to predict both the economic result and thus facilitate the strategic options of irrigators and water managers.

\subsection{Analysis of economic drought risk}

The explanatory model described above (Eq. (1)) is the starting point for the analysis of economic drought risk in each province. If the goodness-of-fit in each geographical unit is robust enough, then the fitted equation can be used to define the distribution function of the harvest's value for the upcoming irrigation season based on the estimated parameters and the model variables known at the time of calculation. Thus, Monte Carlo (Latin Hypercube) simulation models yield distribution functions of production value for the year $t+1$ $\left(I \tilde{P} V_{i t+1}\right)$ under different scenarios of water availability with particular attention to situations of water scarcity. The procedure allows the distributions $\left(I \tilde{P} V_{i t+1}\right)$ to be revised months before the irrigation season $t+1$ begins. These revisions can be performed because the variable $R_{i t}$ is monitored on a weekly basis in each watershed and historical series data are available.

Let $\Delta \tilde{R}_{i, t+1}^{h}$ be the random variable that defines the increase in reserves between the end of season $t$ (in October) and the start of season $t+1$ on May 1 , estimated $h$ months before that date, in province $i$. Thus, the random variable that defines the availability of water for the irrigation season of year $t+1$, evaluated in month $h$, is given by:

$\tilde{R}_{i, t+1}^{h}=\bar{R}_{i t}^{h}+\Delta \tilde{R}_{i, t+1}^{h}$

where $\bar{R}_{i t}^{h}$ is known (storage level $h$ months before May 1 ) and $\Delta \tilde{R}_{i, t+1}^{h}$ is a random variable that can be estimated from historical data of the supply system servicing province $i$. Periods of risk analysis are referred to as $h$. In the applications shown in this work, we obtained results for two sub-periods: 7 months before the beginning of the season (i.e., October 1, 7 months before May 1) and 3 months before the beginning of the season (February 1). It should be noted that our modeling approach allows for weekly or monthly time steps because historical reservoir data are recorded on a weekly basis.

Thus, the simulated stochastic value of production $I \tilde{P} V_{i, t+1_{i}}^{h}$ for season $t+1$ of province $i$ at $h$ months before the beginning of the season is based on the following equation:

$I \widetilde{P} V_{i, t+1}^{h}=\hat{a}_{i}+\hat{b}_{i} T_{t+1}+\hat{c}_{i} \tilde{R}_{i, t+1}^{h}+\hat{d}_{i} G_{i t+1}+\hat{e}_{i} I \bar{p}_{t+1}+\tilde{u}_{i}$

$\tilde{R}_{i, t+1}^{h}$ is defined according by Eq. (4) and accounts for the uncertainty related to water supply. The error model $\tilde{u}_{i}$ is based on the error structure assumed in Eq. (1). $G_{i t+1}$ is groundwater levels (only in the provinces where groundwater provides a significant proportion of irrigation water), projections of groundwater are the values obtained by the trend followed by previous years' depth of the water table (piezometric levels of key aquifers in the province).

Because $I p_{t+1}$ is an ex-ante measure, the price index is assumed to be a simple moving average of the previous two seasons, as shown in Eq. (6). We have used the previous two seasons because they give a more accurate prediction of the price index in the following year (compared with historical data).

$I \bar{p}_{t+1_{i}}=\frac{I p_{t, i}+I p_{t-1, i}}{2}$

\section{Drought characterization in the study areas}

Prior to presenting the results of our ex-ante economic projections for irrigated agriculture, we provide a graphical and numerical description of the variation of water resource availability and of the production. We selected six Spanish river basins where irrigated agriculture is the main use of water resources and is highly dependent on water management decisions by the River Basin Authorities. The selected basins are Guadalquivir, Guadiana and Duero (discharging to the Atlantic Ocean) and Júcar, Ebro and Segura, which are Mediterranean basins (Fig. 1). The basins analyzed here have been grouped into two categories due to differences in climatic features between drainage areas. The percentage increases of reservoir levels described above are reported for two sub-periods: October (end of irrigation season $t$ ) through May (beginning of irrigation season $t+1$ ) and February through May. Thus, one can see how the probability of a certain increase in storage level changes as we approach the start of the irrigation season (Table 1).

The seasonal pattern of rainfall determines the variability of reservoir inflows across the basins. Table 1 reports the statistical measures of the percentage change in reservoir storage levels in the selected Spanish basins. We also report fitted probability distribution functions (PDFs) for the percentage increase of reservoir levels calculated from monthly storage levels for each reservoir from 1995 to 2009. As an example, Fig. 2 presents the cumulative distribution functions for the two sub-periods to illustrate the differential stochasticity between a river basin that drains to the Atlantic Ocean (Duero) and one that drains to the Mediterranean Sea (Segura). The graph includes four curves, two for each 


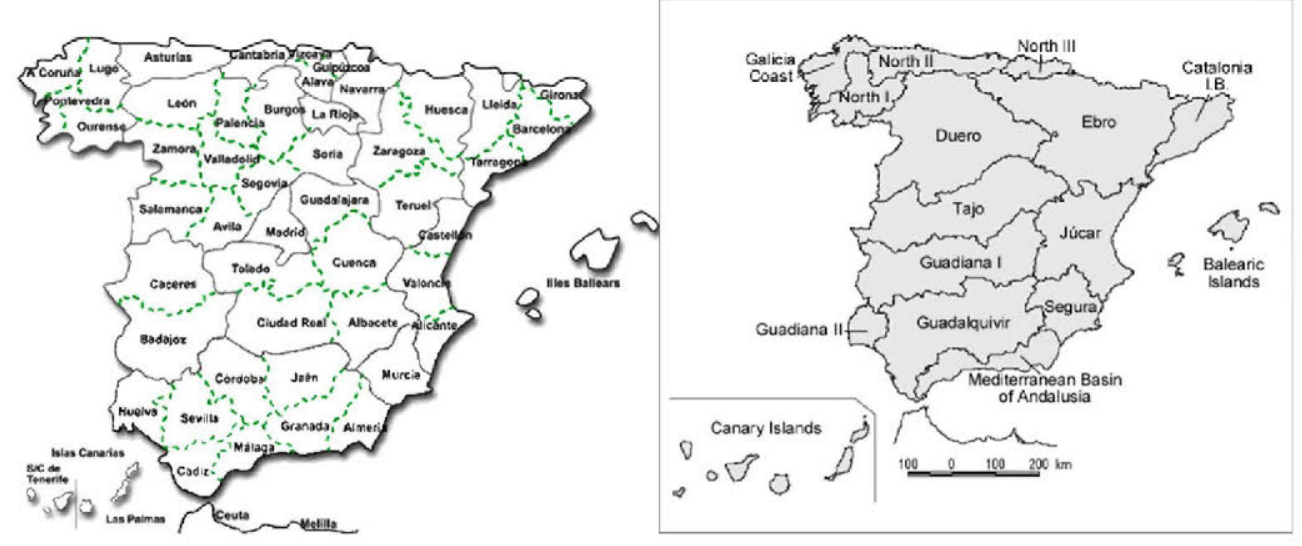

Source: (MARM, 1993-2009).

Fig. 1. Maps of the analyzed provinces and basins.

Table 1

Statistics for the increase of storage levels between October and May ( $\Delta$ oct-may) and between February and May ( $\Delta$ feb-may) and fitted distribution functions (years 1995 and 2009).

\begin{tabular}{|c|c|c|c|c|c|c|c|}
\hline River basins & Mean & St. dv. & $\mathrm{VC}$ & $\operatorname{Var} C F(\%)$ & Perc 5 & Perc 25 & Distribution function (shape, scale) \\
\hline \multicolumn{8}{|l|}{ Guadalquivir } \\
\hline$\Delta$ oct-May & 17.26 & 18.55 & 1.07 & \multirow[t]{2}{*}{21.34} & -22.46 & 4.83 & Triang $(-30,17.7,60)^{\circ}$ \\
\hline$\Delta$ Feb-May & 5.69 & 7.42 & 1.30 & & -8.9 & -0.42 & Triang $(-10,8.1,20)^{*}$ \\
\hline \multicolumn{8}{|l|}{ Júcar } \\
\hline$\Delta$ Oct-May & 10.25 & 10.14 & 0.99 & \multirow[t]{2}{*}{21.26} & -15.77 & 4.17 & Beta General $(5.9219,4.414,-30,40)^{*}$ \\
\hline$\Delta$ Feb-May & 4.41 & 5.29 & 1.20 & & -3.4 & 0.6 & Triang $(-10,2.7,20)^{\circ}$ \\
\hline \multicolumn{8}{|l|}{ Ebro } \\
\hline$\Delta$ Oct-May & 24.44 & 12.12 & 0.50 & \multirow[t]{2}{*}{90.18} & -12.36 & 16.98 & Beta General $(7.2765,4.8665,-30,60)$ \\
\hline$\Delta$ Feb-May & 9.14 & 8.62 & 0.94 & & -3.02 & 3.6 & Beta General $(2.7875,4.2768,-10,40)$ \\
\hline \multicolumn{8}{|l|}{ Segura } \\
\hline$\Delta$ oct-May & 11.11 & 9.45 & 0.85 & \multirow[t]{2}{*}{21.86} & -17.35 & 5 & Beta General $(2.9289,1.9741,-20,30)$ \\
\hline$\Delta$ Feb-May & 4.93 & 5.11 & 1.04 & & -1.85 & 0.55 & Beta General $(1.9923,2.8564,-5,20)$ \\
\hline \multicolumn{8}{|l|}{ Guadiana } \\
\hline$\Delta$ Oct-May & 13.43 & 15.79 & 1.18 & \multirow[t]{2}{*}{37.42} & -15.45 & 2.8 & Betageneral $(2.0549,2.7956,-20,60)^{\circ}$ \\
\hline$\Delta$ Feb-May & 2.94 & 4.75 & 1.62 & & -2.52 & -1.8 & Triang $(-5,-2.15,15)^{*}$ \\
\hline \multicolumn{8}{|l|}{ Duero } \\
\hline$\Delta$ oct-May & 24 & 20.3 & 0.85 & \multirow[t]{2}{*}{8.34} & -19.5 & 6.8 & Beta General $(3.5429,1.6999,-50,60)^{\circ}$ \\
\hline$\Delta$ Feb-May & 9.33 & 8.55 & 0.92 & & -10.11 & 2.8 & Beta General $(14.502,11.967,-40,50)$ \\
\hline
\end{tabular}

Source: own elaboration based on data reported by the Monthly Hydrological Bulletin (MARM, various years).

$\cdot P<0.1$.

Pdfs of the increase of reservoir capacity Duero and Segura

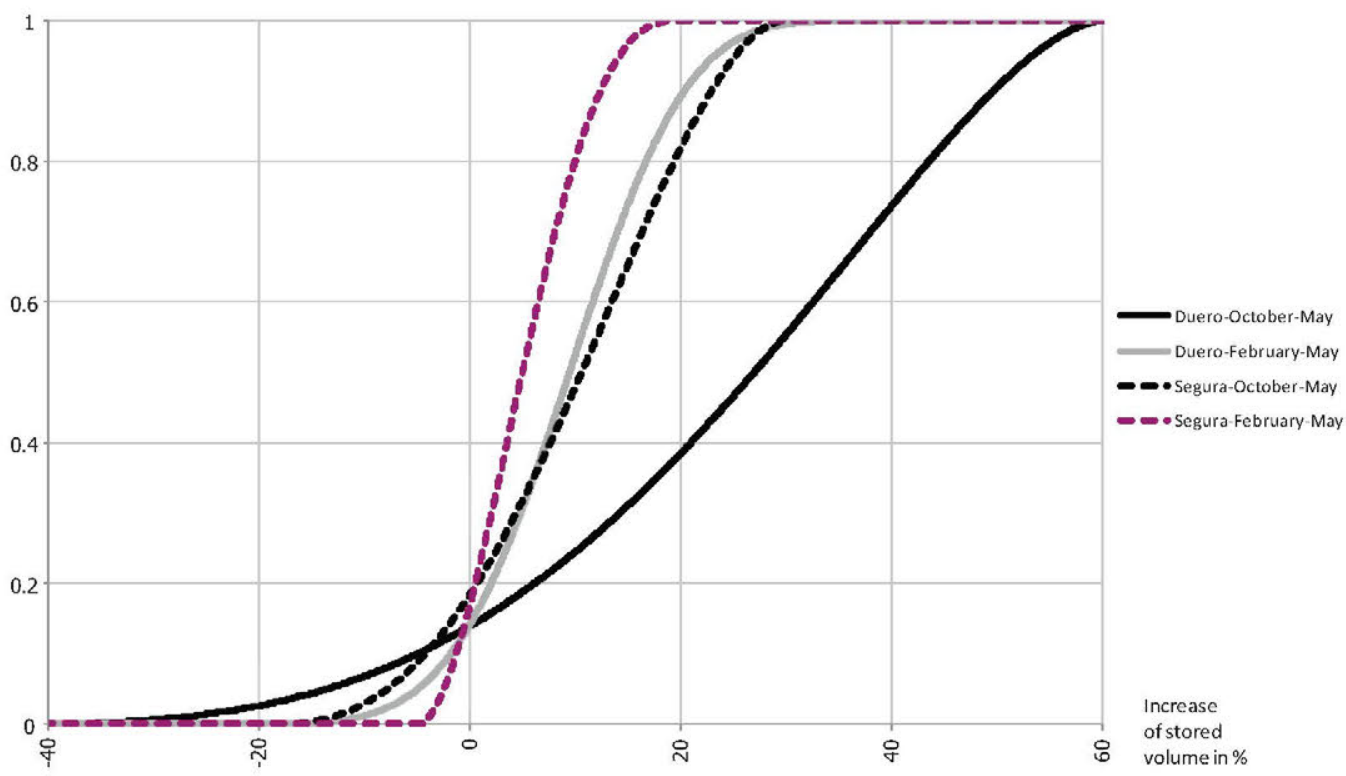

Fig. 2. Probability distribution functions of the increase of reservoir capacity for Duero and Segura. Source: own elaboration with data of the Agricultural Statistics Yearbooks and the Monthly Hydrological Bulletin (MARM, several years). 

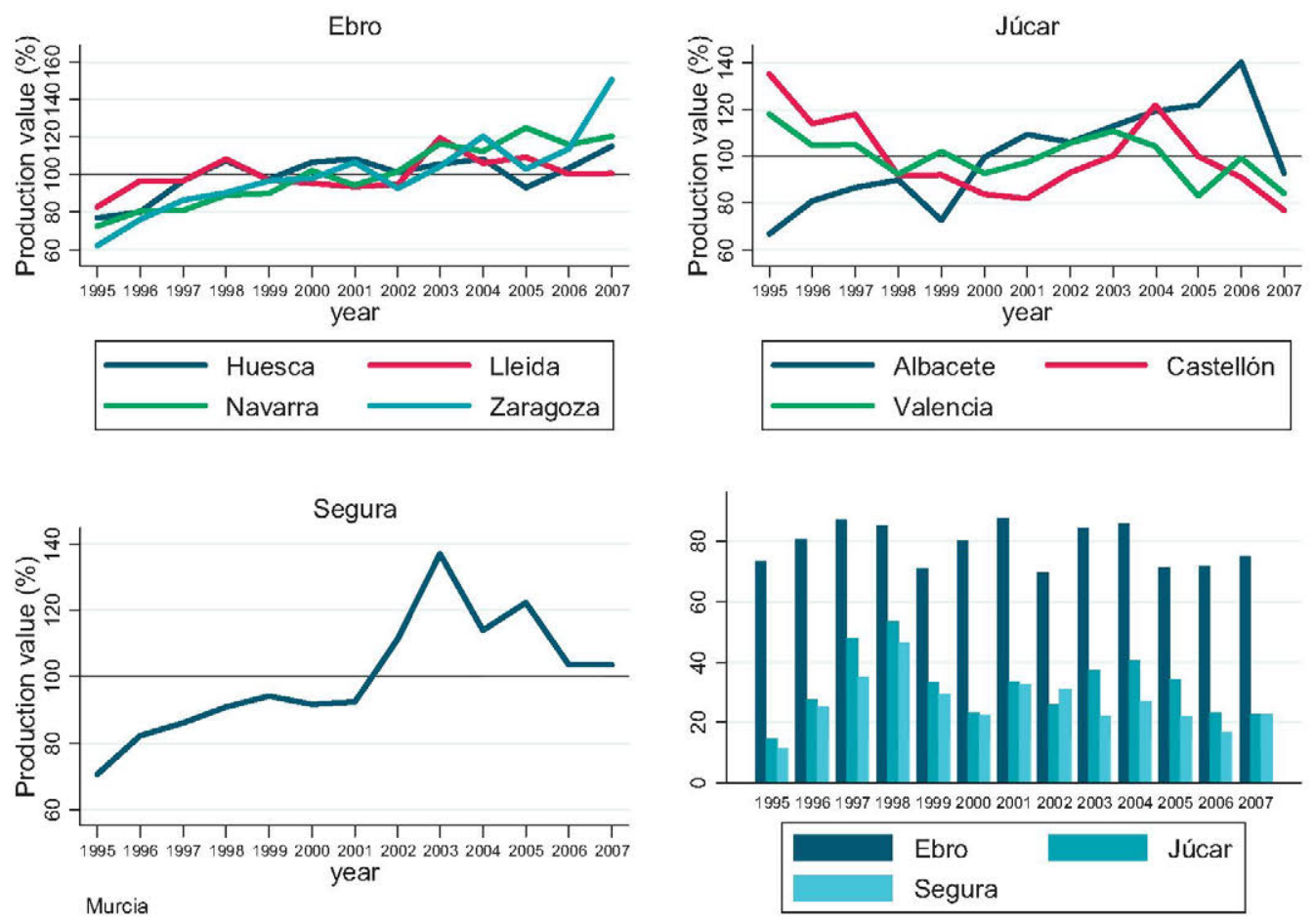

Fig. 3. Production value (referred to base 100) for the Mediterranean provinces and stock levels of the basin's reservoirs (in \% over storage capacity) measured on May 1. Source: own elaboration with data of the Agricultural Statistics Yearbooks and the Monthly Hydrological Bulletin (MARM, several years).

basin: the 7-month (October-May) storage gain and the 3-month (February-May) storage gain. Segura's storage gains are clearly less dispersed than Duero's.

Table 1 shows that in all basins, the coefficient of variation in stock level increases is greater for the February-May period than for the October-May period, although the average increase is smaller. This means that in the short term, there is more variation in storage increases with a much smaller average. Duero and Ebro have the greatest average increases between October and May (both equivalent to about $24 \%$ of storage capacity), whereas the Mediterranean basins Júcar and Segura have the smallest $(10.25 \%$ and $11.11 \%$, respectively). Both the average and variance of winter storage increases are essential to our analysis because they describe the risk borne by irrigators before cropping decisions.

Table 1 also reports the 5 th and 25 th percentiles of the storage increases. We focus on the percentiles in the left tail of PDFs because they are responsible for the downside risk of farms' productivity due to the shortage of water. In all basins, both the short-term (February-May) and the long-term (October-May) 5 th percentiles are negative, which means that storage levels can diminish in at least $5 \%$ of the years. Only in Ebro and Duero are 3-month increases quantitatively important and positive $3.60 \%$ and $2.80 \%$, respectively), but these values differ for the 7 -month period $(16.98 \%$ and. 6.80\%). This indicates that in the Ebro basin, inflows are most likely concentrated in winter (October-February), whereas in the Duero basin they are more evenly distributed between October and May. The main result of this analysis is that the southern basins (Guadalquivir, Guadiana, Segura and Júcar) are more likely to have smaller increases in their reserve levels (even negative in the Guadiana basin), whereas the northern basins (Duero and Ebro) exhibit much higher storage increments. These differences can be explained by the different precipitation regimes, but they are also due to reservoir characteristics (the small reservoirs with less interannual carryover located in the Mediterranean basin will exhibit smaller changes between periods than the large reservoirs located in northern Spain).
Finally, the last column of Table 1 shows the distribution functions that best fit the percentage change in accordance with the $\chi^{2}$ criterion. The PDFs that provided the best fit are Beta General and Triangular, which are bounded functions and allow for positive or negative asymmetries (see Fig. 2). These functions are used in the Monte Carlo simulations using Eq. (5).

In the second part of this section, we analyze the variability of irrigated production value in the 16 provinces selected as the most important in Spain in terms of irrigated production. Irrigated production value (IPV calculated according to Eq. (2). Figs. 3 and 4 present the production values of each province relative to its average production value across years (indexed to 100) as well as the water reserves in each basin measured on May 1 each year as a percentage of reservoir capacity. We have separated the provinces located in basins that drain to the Mediterranean (Fig. 3) from those in basins that drain to the Atlantic (Fig. 4).

The Ebro basin's output value varies by roughly $10 \%$ with no clear trend in the period under review. The average levels of the reservoirs servicing the provinces of Huesca, Lleida, Navarra and Zaragoza are above 60\%. However, drops in reservoir levels in 2002 and 2005 were accompanied by lower production values in these provinces.

The provinces located in the Júcar basin exhibit higher variation in production value due to the price volatility of fruits and horticultural crops. However, Albacete exhibits an upward trend in production value due to the increased presence of vineyards in the province (Gil et al., 2009; Garrido et al., 2010). The storage levels of the reservoirs in this basin are highly variable but always run below $50 \%$, which demonstrates the scarcity of surface water.

Finally, the province of Murcia, which is located almost entirely in the Segura basin, shows large variations in production value. However, the trend is clearly positive because of the growth in value added among irrigated surfaces in the province, especially due to the introduction of more profitable crops like vegetables (Gil et al., 2009; Garrido et al., 2010). The variation in agricultural production 

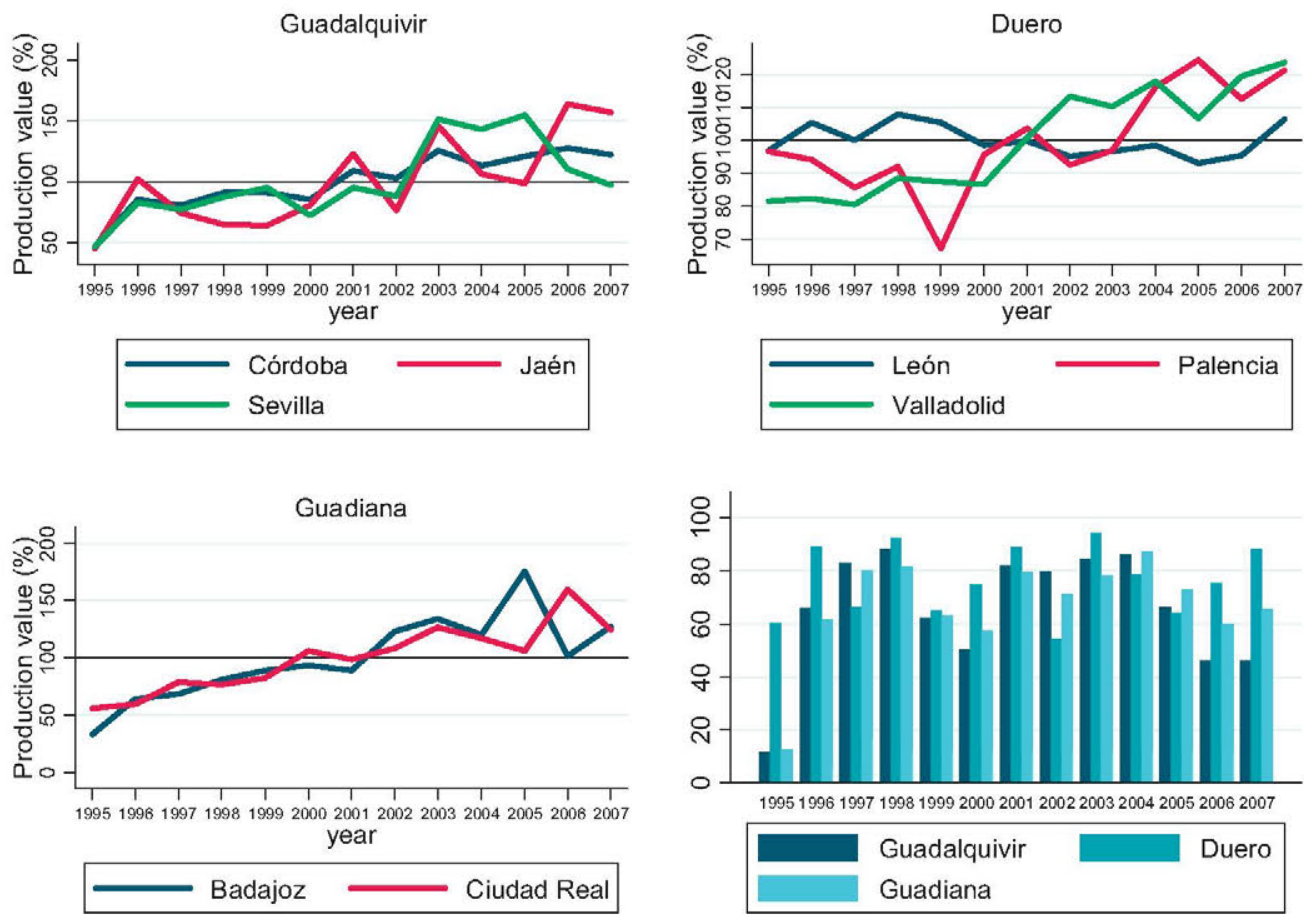

Fig. 4. Production value for the Atlantic Provinces and stock levels of the basin's reservoirs (in \% over storage capacity) measured on May 1. Source: own elaboration with data of the Agricultural Statistics Yearbooks and the Monthly Hydrological Bulletin (MARM, several years).

value is not a function of storage variation in this basin because in most years, the variation is around $20 \%$ of capacity. Groundwater resources contribute at least $30-40 \%$ of all water used in irrigated agriculture.

Fig. 4 presents the data from the provinces located in basins that drain to the Atlantic Ocean. Despite an upward trend in economic productivity, the provinces of the Guadalquivir basin (Jaén, Córdoba and Seville) show strong inter-annual variations, especially in the provinces of Jaén (where olives are the principal crop) and Córdoba. These inter-annual variations are correlated with storage variations that range between 20\% (1995) and 80\% (2003 and 2005). The provinces located in the Duero basin also show changes in production value (Gil et al., 2009; Garrido et al., 2010).

Finally, the provinces of Badajoz and Ciudad Real (in the Guadiana Basin) exhibit small variations in production value (with a rebound at the end of the analyzed period) and a markedly positive trend. This trend does not correspond to the high variability of storage levels, indicating the strategic role of groundwater for mitigating water shortages, especially in the upper basin where the province of Ciudad Real is located.

\section{Results and discussion}

This section first presents the results from the econometric models, one of which is fitted for each province. We then report the simulation results for production value for various years in four distinct cases: two in the north, represented by the provinces of Huesca (Ebro river basin) and León (Duero river basin), and two more provinces in the south, Córdoba (Guadalquivir river basin) and Murcia (Segura river basin). These provinces have substantially different hydrological and economic characteristics.

\subsection{Econometric models}

The dependence of irrigated agriculture on water availability in the selected provinces was measured via econometric models (Eq. (1)). The models take into account that the irrigated area has changed during the study years (a factor that is captured by the time variable) and that commodity prices also influence the production value (a factor captured by the price index). By using aggregate data, Eq. (1) provides an ex-post analysis that quantifies the economic variation directly related to the lack of irrigation water.

Table 2 shows the regression results for the 16 provinces. The coefficients of determination $\left(R^{2}\right)$ together with the level of significance of the explanatory variables provide generally good but somewhat ambiguous results. The last two columns reflect the auto-correlation coefficient ( $r h o$ ) and its statistical significance. The Variance Inflation Factor (VIF) suggests that multicollinearity is not significant in any of the regressions.

The hydrological variable together with the price indices allow the economic impact of drought to be measured in areas highly dependent on stored surface water. However, they also suggest that in some cases price drops are primarily responsible for economic losses even in periods of hydrological scarcity (see provinces like Navarra, Zaragoza, Murcia and Badajoz). Groundwater is an added explanatory variable for the provinces where irrigators use it intensively (Murcia, Albacete, and Ciudad Real), but it was significant only in Murcia. Overall, time (Year) is the most significant (positive) variable for most provinces, and \% (storage level) is significant (positive) in five provinces. The price index, Ip, is significant in seven provinces. The fact that its coefficient is negative in some provinces (Zaragoza and Huesca) suggests that crop price drops result from larger harvests (which in turn may be due to abundant water availability). Crop prices act as a natural hedge for farmers against smaller harvests due to irrigation water shortages.

We also report the elasticity of IPV with respect to the storage level variations (under the column "elasticity \% $R$ " in Table 2). It was evaluated at the means of both variables, as shown by Eq. (7):

$\eta_{R}^{i}=\frac{\partial I P V_{i}}{\partial R_{i}} \frac{\bar{R}_{i}}{\overline{I P V}_{i}}=\hat{c}_{i} \frac{\bar{R}_{i}}{\overline{I P V}_{i}}$

The estimated elasticities should be interpreted as follows: as $\% R_{i}$ increases by $1 \%, I P V_{i}$ increases by $\eta_{R}^{i}$ percent. Elasticity is dependent on the estimated parameter $\hat{c}_{i}$, and is dimensionless. Among 
Table 2

Regression results of the value of agricultural production ( $n=13$ observations).

\begin{tabular}{|c|c|c|c|c|c|c|c|c|c|c|}
\hline \multirow[t]{2}{*}{ River basins } & \multirow[t]{2}{*}{ Provinces } & \multicolumn{9}{|c|}{ Coefficients and significance } \\
\hline & & $R^{2}$ & Year & $\% R$ & GW & Ip & Elasticity $\% R$ & rho & Autocorr & Mean VIF \\
\hline \multirow[t]{3}{*}{ Guadalquivir } & Córdoba & 0.99 & $11392.09^{* *}$ & $624.94^{* *}$ & & 304.95 & 0.239 & -0.69 & $-{ }^{*}$ & 1.3 \\
\hline & Jaên & 0.79 & $29134.07^{* *}$ & -181.26 & & 702.21 & 0.076 & -0.36 & - & 1.14 \\
\hline & Sevilla & 0.85 & $30954.05^{* *}$ & $6196.52^{* *}$ & & $16123.99^{*}$ & 0.575 & -0.13 & - & 1.23 \\
\hline \multirow[t]{3}{*}{ Júcar } & Albacete & 0.88 & $16783.51^{* *}$ & 447.39 & -9874.68 & -9397.951 & 0.000 & -0.22 & - & 1.38 \\
\hline & Castellón & 0.69 & -7357.52 & -100.58 & & 55.79 & -0.002 & 0.53 & + & 1.7 \\
\hline & Valencia & 0.79 & 184.57 & -687.88 & & 3700.34 & -0.058 & -0.49 & - & 1.79 \\
\hline \multirow[t]{4}{*}{ Ebro } & Huesca & 0.95 & $18054.81^{* *}$ & $4597.07^{* *}$ & & $-7320.83^{* *}$ & 0.557 & -0.35 & + & 1.28 \\
\hline & Lleida & 0.82 & 5070.76 & 2882.26 & & $3460.86^{*}$ & 0.364 & -0.16 & $+^{*}$ & 1.2 \\
\hline & Navarra & 0.97 & $7816.25^{* *}$ & 247.43 & & $2813.95^{* *}$ & 0.071 & 0.11 & $t^{*}$ & 2.02 \\
\hline & Zaragoza & 0.97 & $32384.43^{* *}$ & $4461.37^{*}$ & & $-6496.18^{* *}$ & 0.597 & -0.72 & - & 1.25 \\
\hline Segura & Murcia & 0.95 & -3559.17 & 3784.79 & $-459754.6^{*}$ & 5937.66 & 0.062 & -0.47 & $-{ }^{*}$ & 1.21 \\
\hline \multirow[t]{2}{*}{ Guadiana } & Badajoz & 0.96 & $21938.28^{*}$ & 2305.27 & & $12999.59^{* *}$ & 0.192 & -0.53 & $-{ }^{*}$ & 2.16 \\
\hline & Ciudad Real & 0.98 & $29910.07^{* *}$ & 645.38 & -6904.56 & 1168.70 & -0.040 & -0.95 & $-{ }^{*}$ & 1.16 \\
\hline \multirow[t]{3}{*}{ Duero } & León & 0.70 & -1506.14 & $403.35^{*}$ & & 527.92 & 0.141 & 0.20 & $+^{*}$ & 1.31 \\
\hline & Palencia & 0.78 & 1526.66 & 307.89 & & $2967.05^{*}$ & 0.186 & -0.09 & + & 1.55 \\
\hline & Valladolid & 0.83 & $6792.43^{* *}$ & -72.68 & & 1013.63 & -0.017 & 0.20 & + & 2.19 \\
\hline
\end{tabular}

Source: own elaboration.

Note: VIF $>5$ indicates multicolinearity problems.

${ }^{*} P<0.01$.

** $P<0.05$.

those that are significant $(P>0.05)$, the lowest is in León with 0.141 and the highest is in Zaragoza with 0.597 , closely followed by Seville (0.575) and Huesca (0.557). These elasticities suggest that storage level variation (and, by extension, water availability) has a larger impact in the Ebro and Guadalquivir basins than in the Duero basin.

However, in the Segura basin and (to a lesser extent) in the Ebro basin, crop prices also play an important role. To the extent that the model can isolate the effect of price variations over time, the rest of the explained variation is directly attributable to the hydrological variables.

\subsection{Economic drought risk}

Based on Eq. (5) and the fitted PDFs, the estimated autocorrelation coefficient $\rho_{i}$, and the error variance $\sigma_{i}$, we performed Monte Carlo simulations to obtain 10,000 values of $I \tilde{P} V_{i, t+1}^{h}$ for both
LEÓN (2005)
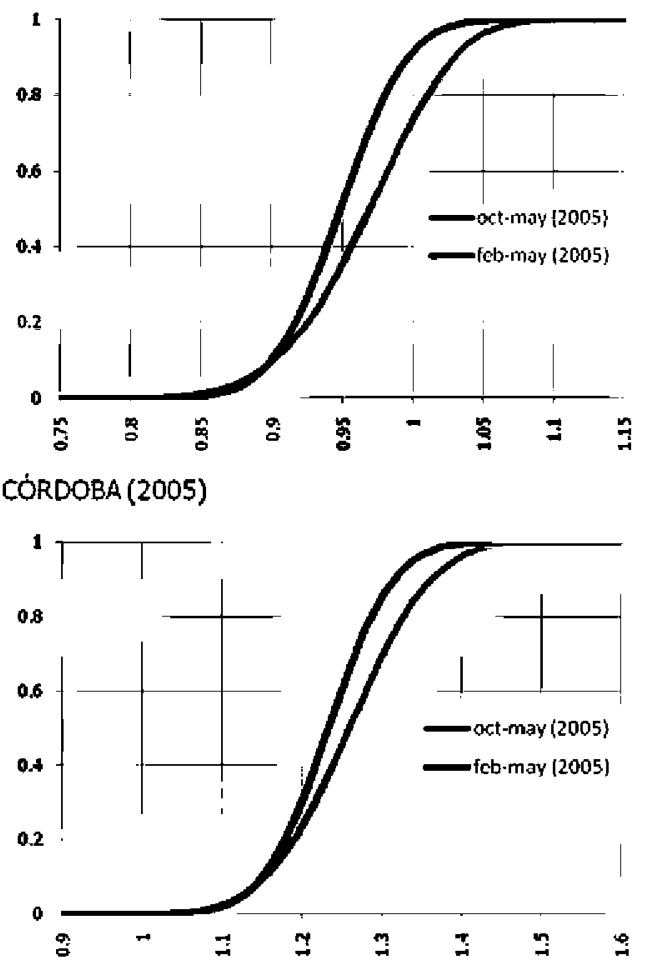

HUESCA (2005)

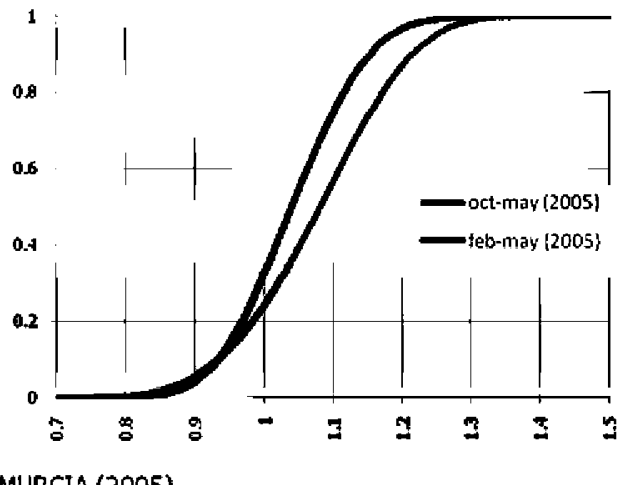

MURCIA (2005)

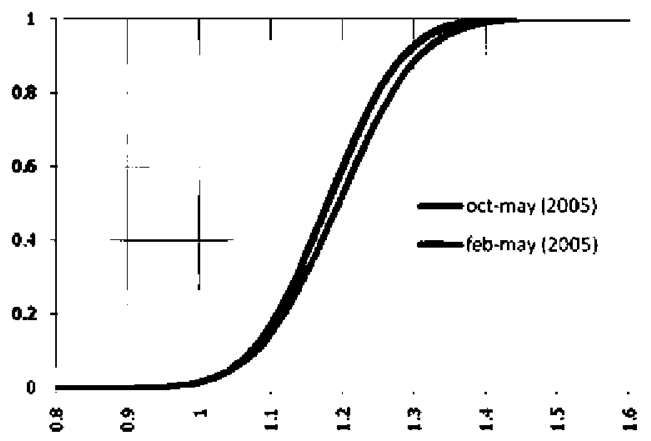

Fig. 5. Cumulative probability of the economic output (in billion euro) for the two ex-ante projections (October and February) for a dry year (2005). Source: own elaboration. 
the short-term period (February-May) and the long-term period (October-May). Note that $I \tilde{P} V_{i, t+1}^{h}$ is unique for each year because the parameter $\bar{R}_{i, t}^{h}$ represents the initial reservoir storage levels, and varies with $t$.

The results of the economic drought risk analysis are presented with reference to two different hydrological years (2005 and 2007, a dry year and a wet year, respectively).

Fig. 5 shows the probability distribution (cumulative probability) of the October-May and February-May production value forecasts expressed in percentage terms (calculated over the average of the studied period). The figure plots the results for the four selected provinces (León, Huesca, Córdoba and Murcia), with the October forecast marked in grey and the February forecast in black.

The top panels of Fig. 5 show the results for the two northern provinces. The graphs depict a similar situation for Huesca and León wherein the projections for the 2005 season worsen from October to February. However, a closer look reveals that the variability is much greater in Huesca (where $90 \%$ of the probability is concentrated between $90 \%$ and $120 \%$ of the historical average, equivalent to an output value of $€ 489$ and $€ 694$ million for the October-May prediction). By contrast, the range in León is limited to $95-100 \%$ of the historical average, i.e., about $€ 40$ million. Thus, the low availability of irrigation water in a dry year causes a downward revision of the expected results. However, Huesca is more vulnerable to droughts than León because its economic results are more dependent on the hydrological variable, as we anticipated in the drought characterization section (due to different elasticities, $\eta_{R}^{i}$, as shown in Table 2).

The bottom of Fig. 5 shows the two provinces selected in the south of the Iberian Peninsula. Córdoba's projection in a dry year (2005) clearly shows that the October PDF is less favorable than the February PDF. By contrast, in Murcia, both projections are very similar. In this province, the joint use of surface and groundwater sources provides a much more secure water supply, leaving the price factor as the major source of economic instability (as shown by the coefficients of Murcia's regression model reported in Table 2).

A more detailed risk analysis in the Ebro basin (represented by the province of Huesca in Fig. 6) reflects the consequences of a dry period. The analysis for 2005 reported an average change in the expected production value between October and February of around $-€ 20$ million. The actual production value of the province calculated from the official statistics was $€ 548$ million, but our exante 5 th percentile was approximately the same value. This means that Huesca had suffered a more severe drought than our model projected, although the projection was within our own prediction interval (5-95\%). Fig. 6 reports a drop of $€ 100$ million in the year 2009 (very dry for the Ebro basin) between the October and February projections. By contrast, in the wet year of 2007, as shown in Fig. 7, the ex-ante 5th percentile estimates a production value increase of $€ 50$ million.

The year 2007 is shown as an example of a wet year (Fig. 7). We thus have a different setting than in 2005, with consequences for the risk profile anticipated for the 2007 irrigation season. On October 1 , storage levels were running very low, so the economic expectations for the upcoming season were low (see Fig. 7). The revision in February changes significantly but quite differently across provinces. In León and Huesca the curves move rightwards, showing a positive change.

However, the situations in Córdoba and Murcia are quite different. Murcia's results do not seem altered as the projection moves from October to February, even though reservoir levels increased from $9 \%$ of capacity in October to $17 \%$ in February. The province's extreme water scarcity does not imply greater economic variability because its tight water supply is predictable. This result is

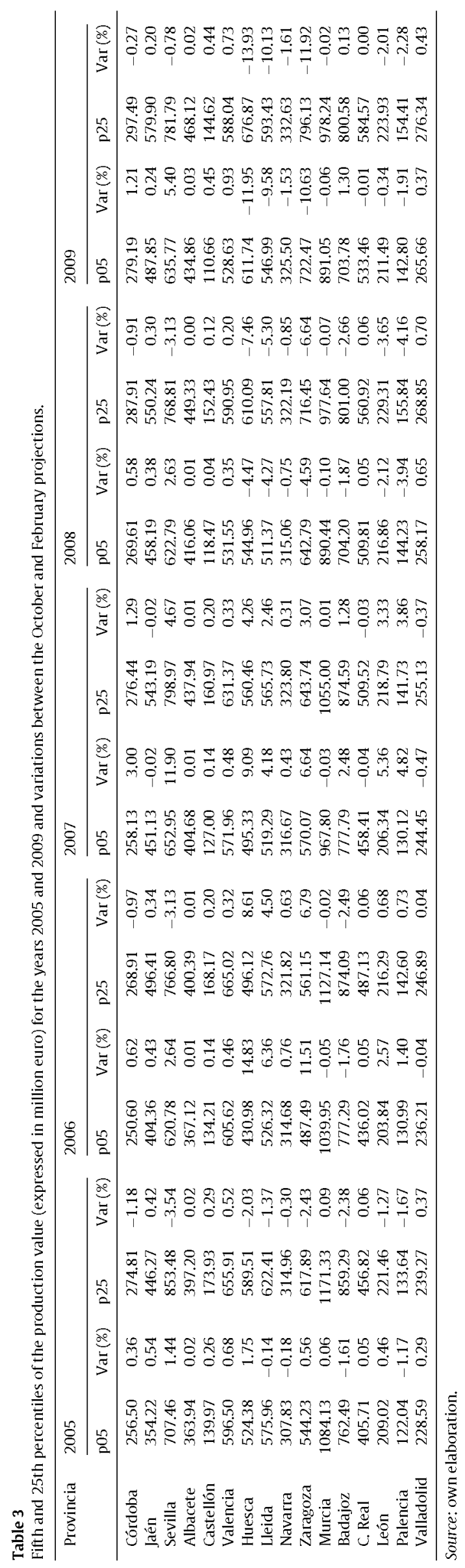




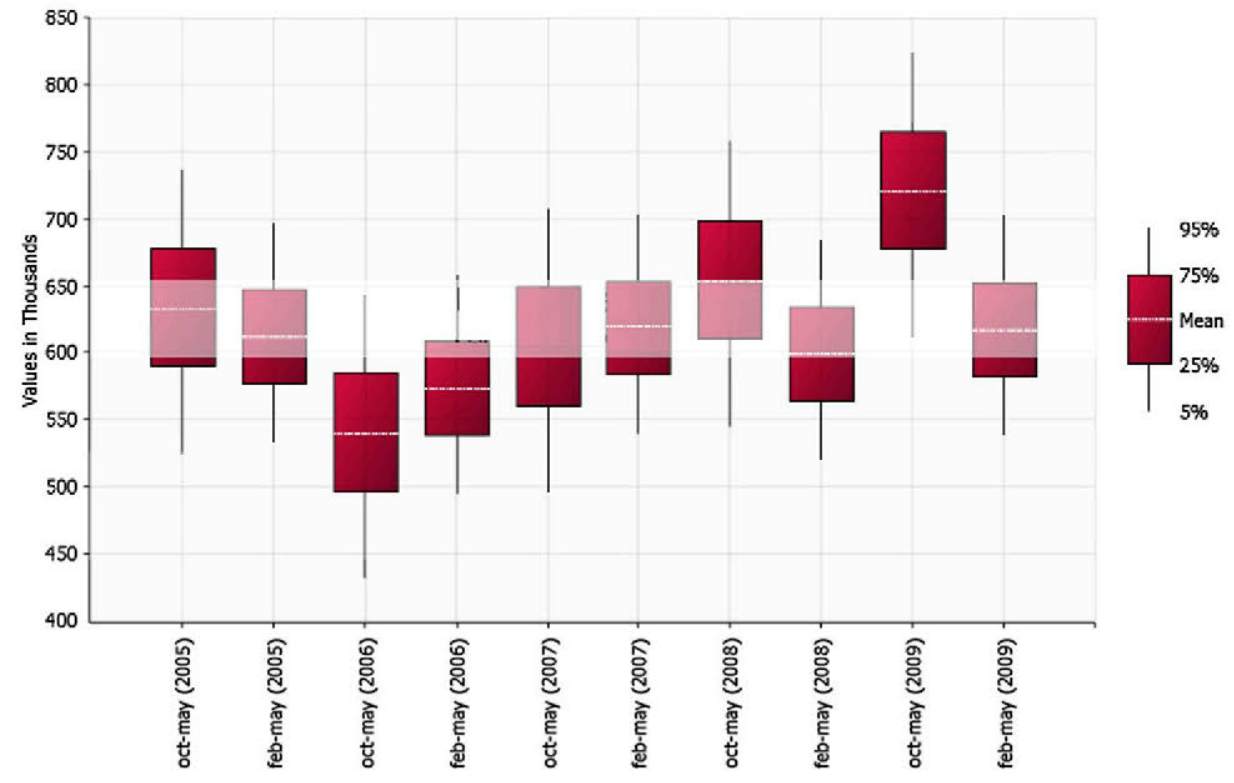

Fig. 6. Box-whisker plots of the production value (in 1000€) of Huesca province (2005-2009).

\section{LEÓN (2007)}

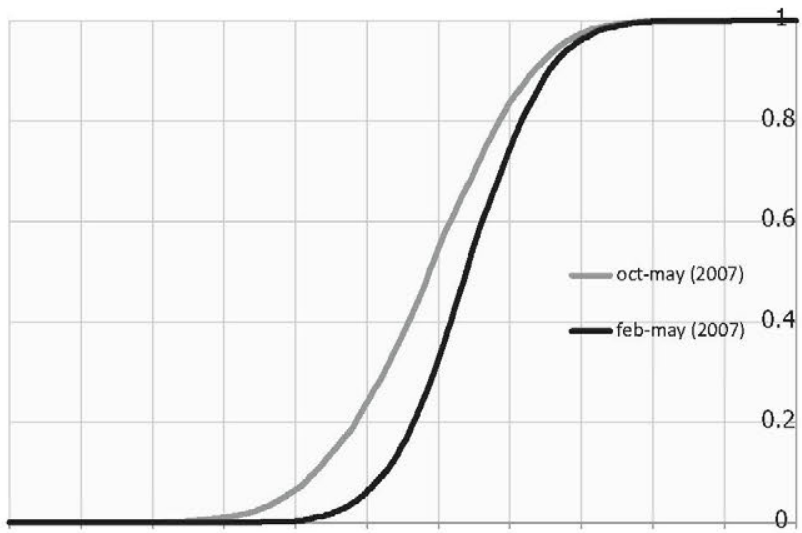

Values in Thousands

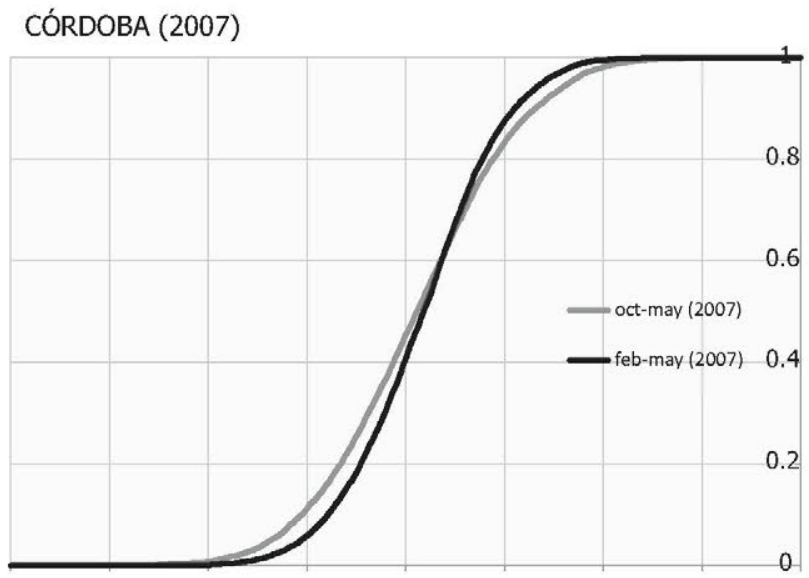

Values in Thousands

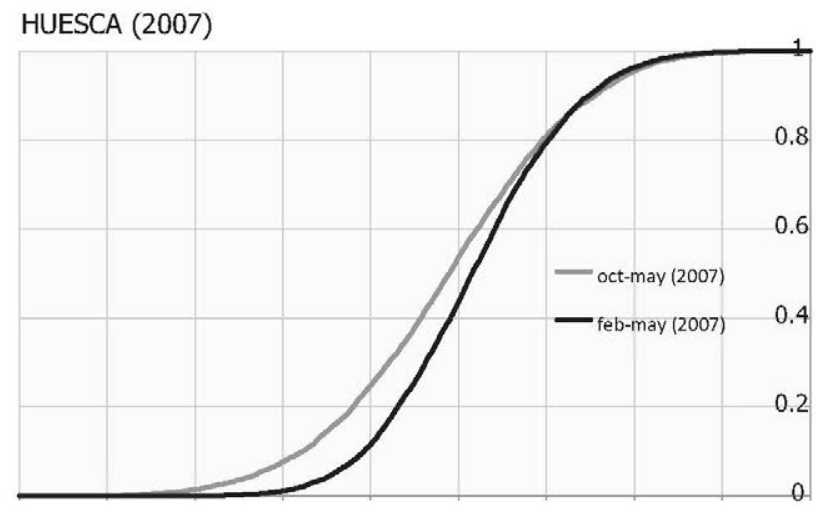

Values in Thousands

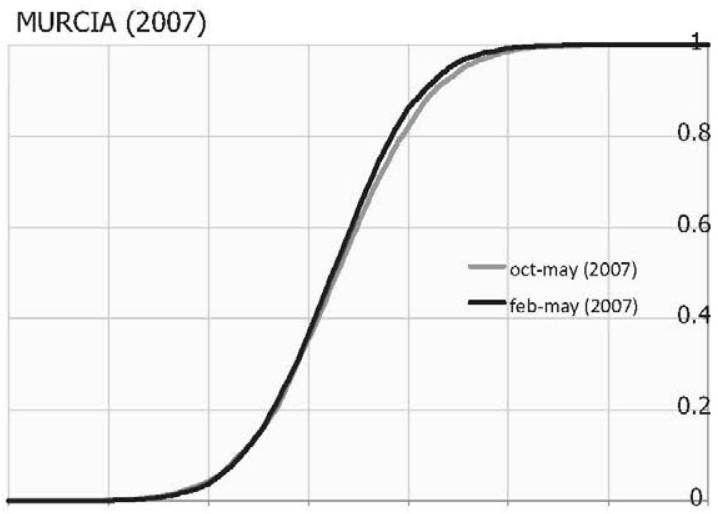

Values in billions

Fig. 7. Cumulative probability of economic output (in $1000 €$ ) for the two ex-ante projections (October and February) for a wet year (2007). Source: own elaboration. 
confirmed by Tobarra (2008), who shows that the insurance premium for a Murcian farmer to ensure water supply would be in the range of $€ 150 /$ ha (a small number compared to the average productivity values in the province in the range of $€ 6000-8000 /$ ha as reported by Gil et al., 2009). In Córdoba, updating the projections from October to February results in a reduction of both tails and a negligible effect on the expected value, improving the accuracy of the projection. While the statistical model (Table 2) predicts a result of $€ 283$ million, which is also the mean of the PDFs (Fig. 7), the realized result was $€ 278$ million, a median prediction for Córdoba.

To present all of the provinces and analyzed years in a snapshot, Table 3 reports the 5 th and 25 th percentiles of the projected economic results (in million euro) for 2005 through 2009. The right column beside each percentile (denoted by $\operatorname{Var}(\%)$ ) is the variation of the percentiles between October and May and between February and May. A negative change of Var (\%) is associated with fattening of the left tail of the PDF. A general inspection of both 5 th and 25th percentiles shows that the left tail does not vary significantly between October-May and February-May. This means that the expectation of extreme results (left tail) does not change during this period.

The largest variations are found in the Ebro basin (the provinces of Huesca, Lleida and Zaragoza), and the largest shift is in Huesca's 2006 results, where the 5 th percentile increased by $14.83 \%$. In Seville, the 5 th percentile increased by $11.9 \%$ between October and February in 2007. From a risk perspective, it is relevant to note that in some provinces (Seville, Huesca, León, among others), the sign of $\operatorname{Var}(\%)$ is different between the 5 th percentile and the 25 th percentile, with the former being positive and the latter negative. This means that the risk profile changes, shifting some probability mass from the extreme left tail to the middle left tail and reducing the chances of the worst possible outcomes.

While the changes in the percentiles are relatively small, a $5 \%$ increase or decrease of the 8-billion-euro output of Spanish irrigated agriculture (totaling the 25th percentiles for 2009) is equivalent to \pm 400 million euros. This is equivalent to the output of an average Spanish province. Thus, these results reinforce the value of this simulation method in that it allows us to monitor economic results and anticipate possible profits and losses for the agricultural sector, which in many cases are significant.

\section{Conclusions}

Spanish irrigated agriculture is subject to water scarcity risk and the impact of droughts. The importance and frequency of drought periods make economic risk analyses, based on sound attribution models of drought effects, especially useful. To the extent that drought impact models establish a statistically significant relationship between water availability and irrigated farm productivity, they can be incorporated into reservoir management models. This approach can assist water managers in running reservoirs and storage facilities.

We showed that the drought index used by Spanish authorities to monitor hydrological and operational droughts is robust enough to support complementary economic analyses. The variation in the production value of irrigated surfaces can be explained by a time variable, a representative price index of the crops grown in each unit (province) and a hydrological variable based on the storage levels of the representative reservoirs. Using this approach, we isolated the economic effects of water scarcity from other causes of reduced economic output (a downward trend due to structural factors such as reductions of farmland and price volatility unrelated to water availability). We found differences in crop value variability across provinces that can be attributed to hydrological variables.
Provinces that rely on groundwater and secure supply sources are more exposed to price volatility than other provinces where the economic output is more dependent on surface water availability.

Our regression models provide sufficient explanatory power for use in risk analyses and for performing ex-ante projections of the economic output of the irrigation sector measured in probability. The hydrological variable (storage levels) can be traced weekly on almost a real-time basis (using the MARM database). By inserting stochastic changes in the storage levels on a monthly basis into the regression models, we developed risk models that connect the hydrological variability with the resulting economic variability.Just as the hydrological state is subject to stochastic processes, the economic performance of the sector can be stochastically connected to the former. An accurate drought attribution model must single out other sources of production variability, especially crop prices.

Multiple drought risk profiles were identified by examining the vast array of hydrological, agronomical and geographical features represented by the 16 Spanish provinces included in this study. For the provinces that rely on surface sources and water storage systems, robust ex ante risk characterizations were performed with clear potential for real-time revision. Managers can generate production value ranges for the next irrigation season at the end of the previous season. The probability distribution functions for economic output can be revised simply by updating the storage information that is recorded electronically. The left tail of farm output's PDF can change in a matter of months. Managers can simulate ex-ante the economic effects of any strategic response to either favorable or unfavorable hydrological conditions. A PDF of the economic impact of augmented environmental flows (in terms of foregone agricultural benefits) can also be generated if such flows are required to secure wildlife and habitat conservation at the expense of the irrigation water supply.

However, the intra-annual risk predictions have lesser potential for the provinces that rely primarily on groundwater resources. Water tables vary less than surface storage levels, and the effects of drought manifest for longer periods (see Llamas and Custodio, 2003). In the short term, price volatility is a much larger source of revenue instability for farmers, especially if they grow fruits and vegetables, as evidenced by the results of Murcia (in southeastern Spain). Drought indices based on reservoir levels are obviously poor indicators for users relying on groundwater.

Drought risk analyses vary depending primarily on water supply and secondarily on weather characteristics. We conclude that the ability to revise ex-ante projections is the key to obtain accurate information. We have emphasized the ease of these calculations and their potential for ex-ante drought management in all of the provinces that were analyzed.

Natural extensions of this work would include developing risk management instruments including insurance, derivatives and/or option contracts. This type of instrument would permit a portion of the supply risk to be transferred to the financial, insurance and/or reinsurance markets.

\section{References}

Alcalá Agulló, F., Sancho Portero, I., 2002. Agua y producción agrícola: un análisis econométrico del caso de Murcia. Revista Española de Estudios Agro-sociales y Pesqueros 197, 129-158.

Berrittella, M., Hoekstra, A.Y., Rehdanz, K., Roson, R., Tol, R.S.J., 2007. The economic impact of restricted water supply: a computable general equilibrium analysis. Water Resources Research 41 (8), 1799-1813.

Calatrava, J., Garrido, A., 2005. Modelling water markets under uncer tain water supply. European Review of Agricultural Economics 32 (2), $119-142$.

Garrido, A., Gómez-Ramos, 2009. A. Risk sharing mechanisms supporting planning and policy. In: Iglesias, A., Cancelliere, A., Cubillo, F., Garrote, L., Wilhite, D. (Eds.), Coping with Drought Risk in Agriculture and Water Supply Systems. Springer, EEUU, pp. 133-151. 
Garrido, A., Llamas, M.R., Varela-Ortega, C., Novo, P., Rodríguez-Casado, R., Aldaya, M.M., 2010. Water Foot print and Virtual Water Trade in Spain. Springer, Nueva York.

Gil, M., Garrido, A., Gómez-Ramos, A., 2009. Análisis de la productividad de la tierra y del agua en el regadío español. In: En Gómez-Limón, J.A., et al. (Eds.), La economía del agua de riego en España. Fundación Cajamar, p. 528.

Gómez, C. Tirado, D., Rey-Maquieira, J., 2004. Water exchanges versus water works: insights from a computable general equilibrium model for the Balearic Islands. Water Resources Research $40(10)$.

Gómez-Ramos, A., Garrido, A., 2004. Formal risk sharing mechanisms to allocate uncertain water resources: the case of option contracts. Water Resources Research, 40.

Goodman, D.J., 2000. More reservoirs or transfers? A computable general equilibrium analysis of projected water shortages in the Arkansas River Basin. Journal of Agricultural And Resource Economics 25 (2), 698-713.

Iglesias, A., Garrote, L., Cancelliere, A., Cubillo, F., Wilhite, D.A., 2009. Coping with Drought Risk in Agriculture and Water Supply System. Springer, New York.

Iglesias, E., Blanco, M., 2008. New directions in water resources management: the role of water pricing policies. Water Resources Research 44 (6).

Iglesias, E., Garrido, A., Gómez-Ramos, A., 2003. Evaluation of drought management in irrigated areas. Agricultural Economics 29, 211-229.

Iglesias, E., Garrido, A., Gómez-Ramos, A., 2007. An economic drought management index to evaluate water institutions: performance under uncertainty. The Australian Journal of Agricultural and Resource Economics 51, 17-38.

Llamas, M.R., Custodio, E. (Eds.), 2003. Intensive Use of Groundwater: Challenges and Opportunities. Balkema Publishing Company, Amsterdam.

Lorite, I.J., Mateos, L., Orgaz, F., Fereres, E., 2007. Assessing deficit irrigation st rategies at the level of an irrigation district. Agricultural Water Management 91 (1-3), 51-60.
MARM, 1995-2007. Anuarios de Estadística del Ministerio de Medio Ambiente y Medio Rural y Marino. (Agricultural Statistics Yearbooks, Spanish Ministry of the Environment and Rural and Marine Affairs).

MARM, 1993-2009. Boletín Hidrológico Semanal del Ministerio de Medio Ambiente y Medio Rural y Marino. (Monthly Hydrological Bulletin, Spanish Ministry of the Environment and Rural and Marine Affairs).

Martínez-Cachá, A, 2004. Impacto económico de las sequías en el sureste agrario español. Fundación Universitaria San Antonio, Murcia, p. 187.

Mejías, P., Varela-Ortega, C., Flichman, G., 2004. Integrating agricultural policies and water policies under water supply and climate uncertainty. Water Resources Research 40,7.

Peck, D.E., Adams, R.M., 2010. Farm-level impacts of prolonged drought: is a multiyear event more than the sum of its parts? Australian Journal of Agricultural and Resource Economics 54 (1), 43-60.

Pérez y Pérez, L., 2007. Evaluación de los efectos socioeconómicos de la sequía en la cuenca del Ebro. In: Confederación Hidrográfica del Ebro ,. Oficina de Planificación Hidrográfica.

Quiroga, A., Iglesias, A., 2009. A comparison of the climate risks of cereal, citrus, grapevine and olive production in Spain. Agricultural Systems 101, $91-100$.

Rubio Calvo, E., Abad, J., Gimeno, Y., García, M., Oliva, C., 2006. Repercusión de la sequía en los riegos del Alto Aragón. Riegos del Alto Aragón.

Salami, H., Shahnooshi, N., Kenneth, J.T., 2009. The economic impacts of drought on the economy of Iran: an integration of linear programming and macroeconometric modelling. Ecological Economics 68, 1032-1039.

Tobarra, P., 2008. Gestión del recurso natural agua en situaciones de información asimêtrica e incertidumbre. Doctoral Thesis. Universidad Politêcnica de Cartagena, Spain. 